\title{
OPINION
}

\section{Women in Science}

\author{
Genome Biology* \\ Listen to a podcast with Professor Susan Greenfield on her experience in academia and her views on how to succeed in a research science \\ career: http://genomebiology.com/sites/3001/download/WomeninscienceMar2012.mp3
}

\begin{abstract}
To coincide with International Women's Day, Genome Biology asked several female scientists about their experience of an academic career, how they managed to balance an active research career with family life, and what should be done to encourage more women to pursue research careers to stop the 'leaky' pipeline.
\end{abstract}

\section{Can you tell us a little about your experience of working in science research?}

CD: I enjoyed biology at school and was fascinated by marine biology programs on TV when I was a teenager. I therefore chose to do a marine biology degree at university. However, we had to do biochemistry courses during the first year - something I had never been introduced to at school. I enjoyed those so much that I switched courses to Biology specializing in Biochemistry. A second year practical assaying electron transport in isolated chloroplasts hooked me onto plants. I stayed at the same university to do a $\mathrm{PhD}$ in chloroplast development but wasn't really considering a research career at that stage. However, my research supervisor spent a year on sabbatical in California and all her stories of the place intrigued me. I jumped at the opportunity to do a postdoc in Berkeley and got completely hooked on research. I have found a science career extremely rewarding. It keeps me happy and interested and, as such, a much nicer person to be around! In my view having other passions in life apart from your children makes you a better parent. I have never felt any prejudice at work or detected a glass ceiling - if anything the opposite.

MO: I have had a privileged life in science. I entered science just as the field of molecular biology was being founded. My early experiences as a postdoc in Jim Watson`s lab at Harvard and as a staff scientist in Sydney Brenner and Francis Crick's division at the Laboratory of

${ }^{*}$ Correspondence: editorial@genomebiology.com

Genome Biology, BioMed Central, 236 Gray's Inn Road, London WC1X 8HB, UK
Molecular Biology in Cambridge and at Cold Spring Harbor Laboratory in the late 60 s and early 70 s were enormously important for my later career. World-class science was going on all around me, lab interactions were science driven, and the excitement at each new result was infectious. Gender was not an issue and there were virtually no female role models

AO: I started my research career with a PhD in physics, which is a typically male-dominated field. However, in my department at the University of Melbourne there was a small, but strong, core group of women who were at that time actively promoting and supporting women in physics. The gender imbalance is evident in physics well before the $\mathrm{PhD}$ level, so when I subsequently moved into biomedical science I felt that I was surrounded by women. However, it is clear that even in this field the gender gap widens at the level of senior post-doc and labhead, as has been shown by the famous 'scissor' plot (Figure 1) [1,2]. Personally, I have been lucky enough to be supervised in groups that are actively supporting women's roles in science. I had excellent mentors in that regard with Professor Rachel Webster as my $\mathrm{PhD}$ supervisor and Professor Terry Speed as my Division Head in bioinformatics, both of whom passionately support women. I'm sure this made my passage through the early part of my career relatively easy. However, when I reached about the age of 30 questions started to form for me: how can I have a family and a career in science? Do I have to be a superwoman or a genius to have both? If I try to do both will one suffer? Many of the senior women I saw had excellent careers but what I considered an undesirable family life. Being an optimist, however, I was hopeful it could be done. I took the plunge and I now have two small children aged almost 5 years and 2.5 years. The timing of having kids really coincided with establishing my independent career and getting my own lab.

JT: Since 2001 I have been Director of the EMBLEuropean Bioinformatics Institute in the UK, and I also have a research group that focuses on understanding the structural basis of protein function and the molecular basis of ageing. I am originally from northern England, and my academic undergraduate background is physics. 


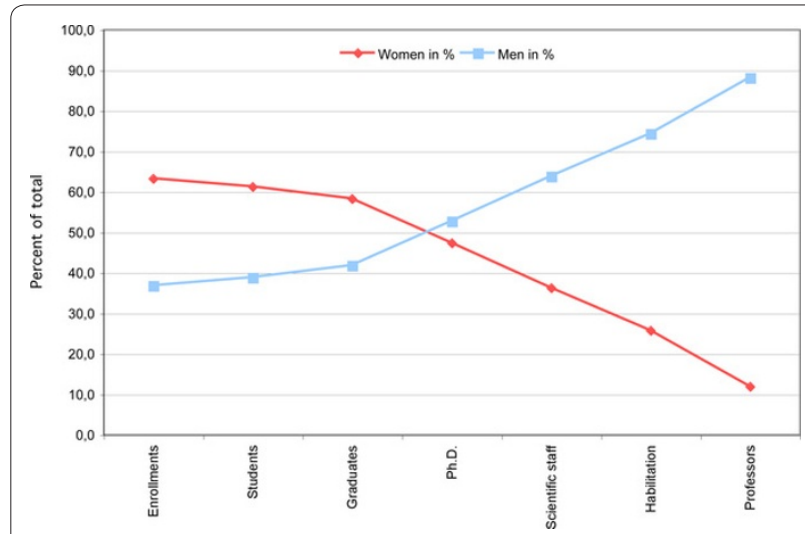

Figure 1. The 'scissors' pattern of gender distribution within career stages in biological sciences at German universities. The figure shows the percentage of male and female university students through graduation, PhDs awarded, scientific staff (includes post-doctoral fellows, some junior group leaders, and research scientists with university or PhD degrees), Habilitation (awarded for research accomplishments following the PhD as well as teaching experience, which is often a pre-requisite for university professorships in Germany), and professors [1]. A similar pattern has been found in other countries, for example, Australia [2]. For further information on gender equality in science in the EU, see [3].

My PhD was in biophysics, combining 'wet' and 'dry' work to study nicotinamide adenine dinucleotide (NAD) at the National Institute for Medical Research in London. In the late 1970s, in the very early days of computational biology and with two small children, I was fortunate to work on protein structures with Sir David Phillips at the University of Oxford. I then took a fellowship at Birkbeck College in London, later moving across the road to University College and, together with my colleague Christine Orengo, created a database resource called CATH that classifies proteins according to their structures and evolutionary relationships. I was appointed Professor and became Director of the Biomolecular Structure and Modeling Unit; at that time my children were older and more independent. For a short (and rather exciting) time, I founded a start-up called Inpharmatica, using computational approaches to look for drug targets. I became a Fellow of the Royal Society in 1999, and not too long after came to EMBL-EBI. I now have the very good fortune to be an active grandmother, doing the research I love and working with exceptionally good people in a field that is undergoing radical change. For the record, I'd just like to say that as a scientist I've never suffered gender-based negativity from a scientific colleague. If anything, being female has been a boon to my career, simply because there aren't many of us. If you're the only woman on a conference programme, everyone remembers you and you are more likely to be asked to give talks and sit on committees. However, I acknowledge that others may not have been so fortunate.

\section{How have you balanced your academic career with family life?}

CD: I waited to have children until I had a small functioning group - I found it much easier to balance work and family when I wasn't trying to do experiments. It is very difficult gauging how long experiments will take - there are often unexpected complications in the middle of a protocol - so having to leave work at defined times multiplies the stress. Many aspects of managing a lab can be done at all times of day and night so can be woven into your other commitments. I would always recommend getting as much home help as possible so when you are not at work you can spend all of your time relaxing with your partner/children.

MO: Work-life balance is a term that has crept into science only recently. It is an admirable goal but difficult to achieve if you aim to be a top scientist or indeed reach the top in most professions. However, scientific research is a career where times of intense activity alternate with times where there is more time to think in depth about the next set of experiments. One can regulate the stress to some extent by regulating the size of the group and by good infrastructure. And time away from the lab allows one to define ones own priorities both in the lab and more generally.

AO: I think it is challenging to combine a career and family life; however, it also keeps me happy, fulfilled and balanced. Before I had children I found it a very daunting prospect to consider combining a research career and a family. I talked to my friends and many felt the same way. However, I know that if I was totally immersed in one or the other I would feel discontented - that there was something missing in my life. One important aspect, enabling me to achieve a balance, has been a supportive husband who takes on many of the home duties. I think the problem of balancing career and family comes down to a lack of time to do everything that you want to do. At times I felt very disempowered because I never had enough time. One of my tricks now is to be very conscious about what I want to invest time into, whether it be paying for a cleaner, opting for a sleep-in rather than a morning jog; leaving the lab early and working later in the evening, rather than leave the kids in childcare for longer. I make time to watch TV shows that I like but don't just watch it for the sake of it. I make sure I have some time in the week to do nothing much. I actively make time to do the things I really value and my priorities in life are much clearer. Perhaps because I don't do any lab work, I have more flexibility about when and where I can work, which is an advantage of bioinformatics. I tend to think that science is actually a good career to combine with children because hours are usually very flexible. I also remind myself that I'm judged on what I produce, not what other people see me doing. My efficiency at 
work has definitely increased since I've had children and employing women with children can be good value for money because they are often dedicated and productive.

JT: Finding a healthy balance between work and personal life is a struggle for anyone in a professional career, and science is no exception. This balancing act is a greater challenge for women because, even in these enlightened times, it is still primarily to them that the burden of childcare falls, just as it was when I was bringing up my children in the 70s and 80s. A successful career in academia does inevitably involve working long hours, but it can be more flexible than other professional careers, for example, a medical doctor who has to be on the wards at certain times or an accountant that has to meet clients. I was lucky enough to be able to gain a parttime Fellowship at Birkbeck College when my children were young - that was a balance that worked brilliantly for me. I had time to really focus on my research and also to be part of my children's life, and that was terrific. I felt I was productive in my career, I met a set of people I never would have known otherwise, and having time with my family enriched my life and helped me to absorb the stresses and strains of a demanding job (and vice versa!).

Whether a scientist is male or female, we all have to arrange our lives around family and work commitments and somehow keep the plates spinning. I find that maintaining a work-life balance, even now, remains a huge challenge; it's a continual battle. But science is a wonderful career and I can honestly say that I've never had a boring day - it's a privilege to be paid to explore the frontiers of scientific understanding.

\section{How do you strike the balance between your career goals and those of your partner?}

CD: That's always a tricky one. My partner is slightly older than I am and so a post-doc ahead of me so to a certain extent his career goals dominated our thinking during the step of 'getting our own labs'. We interviewed at several places and were lucky enough in the end to have the choice of three places offering us both a position. We accepted positions in the UK at two separate institutions on a shared site. This let us develop our own groups and be viewed quite independently of each other. I think it is important as a couple to have your own very distinct scientific identity. I am always amused when I meet people who do not know we are married.

MO: We came to Germany because my husband had an offer from the Max Planck Society as a Director. These posts come with full funding for staff positions and for equipment and consumables. This allowed us to focus on research that defined the existence, arrangements and protein composition of cytoskeletal structures in cells and tissues. Later we developed new antibodies that distinguished the different intermediate filament proteins and proved useful for human tumor classification. We benefited enormously from the freedom given us by the Max Planck Society to pursue our own scientific goals and the fact that the Society did not prohibit couples from working in the same department.

AO: Having a family is always a balance because you are not only thinking of yourself when you make a decision but you are thinking of the other members of your family and how decisions affect them. My husband is a teacher, which means he has a very flexible job in terms of where to live but it's not flexible in working hours or holidays. We made the choice to stay in Melbourne near to both of our families. While living overseas might have been the best choice for the advancement of my career, there were opportunities here and the enormous benefit of having willing relatives to help out with our children. Having our family and friends nearby has been great for us, our careers and the well being of our children.

JT: We all, men and women, carry a set of expectations about ourselves and others that can have a powerful influence on the choices we make. Many women scientists are keen to work part-time, like I did, or to give up work entirely to take care of their children. And of course, conversely it can be difficult for men to choose to take on the childcare because of the weight of expectation that this is not what men have typically done in the past. My husband worked locally, whilst I commuted - so as with most families - we muddled through - responding each day to that day's challenge. Work-life balance is not something that just happens. It involves the efforts of a number of players: the employee, the organisation for which the employee works, the family with whom the employee lives, and the society in which all are embedded. It involves mutual understanding and respect between all of these people.

\section{What do you think can be done to plug the 'leaky' pipeline, whereby many female scientists leave active academic research early in their careers?}

CD: I think mentoring is the key to plugging the leaky pipeline. On the whole women need a lot more support and reassurance - it seems to be an inbuilt thing - given a glass half full situation most men push forward, whereas most women hang back. Building their self-confidence and self-belief is really important. Women should strive to constantly work outside their comfort zone - this is the best way to increase one's self-confidence as quickly as possible. I did not have a female mentor but I was lucky enough to work in an institution with a flat management structure and extremely supportive colleagues. Everyone really looked out for each other. On the whole scientists like to work in an environment with a good gender balance - it helps to generate a more interactive, supportive and thus productive scientific community. 
MO: There is a leaky pipeline for women in science particularly in Germany [3]. Necessary measures to improve the situation include more realistic assessments of career possibilities (active mentoring on a one-to-one basis but also more active career advice to those who want to use their science qualifications but who do not aspire to the junior group leader/professor pathway). Women still hold only around 14\% of the full professor positions in universities and in the research institutes the numbers are lower (for instance, only around 8\% of current Max Planck directors are female). You have to change the institutions but academic institutions are very conservative and are slow to change without pressure from those at the top or from outside. Above all one has to get the argument across that it is wasteful, expensive and unfair to educate and train large numbers of female scientists and then not use their talents in the job market or provide equal access to the top jobs.

AO: I wish I had a solution to the issue of females leaving the profession but I don't know what the answer is. I suspect there is a combination of things to address that individually may only make a minor difference but will add up to a greater retention of women into senior roles. For myself my mentors have meant a lot to me, whether they are female or male, but knowing they are supportive when I'm faced with challenges makes a big difference. As a post-doc I was lucky enough to have the opportunity to have a round table discussion with Elizabeth Blackburn (Nobel Laureate) who gave us a great insight into combining a family life and a stellar science career. I think it's pretty clear that role models are important. When there are senior female role models, such as Elizabeth Blackburn, in a field, it tends to attract more women, as can be noticed in the telomerase field.

I also think that opportunities for women to get together and talk about the challenges they face can be very helpful. When I was a post-doc at the Walter and Eliza Hall Institute, the Director, Doug Hilton, brought in some new initiatives to address the problem, including paying for childcare and paying for carers to attend a conference with you. These are very generous and proactive initiatives, which I believe will have long-term payoffs for the institute but are largely not replicated in other workplaces. These sorts of initiatives not only help practically but also help make you feel valued at a time that can be difficult to feel like you fit into the scientific culture. I believe there still needs to be a change in attitude of people and organizations and this is likely to take some time but hopefully we are moving in the right direction.

JT: I think flexibility of approach to working practices (both from young scientists and their mentors) is probably the most important ingredient towards making it possible for scientists to have fulfilling careers and fulfilling lives outside science. This includes flexibility of how and when young scientists work, flexibility of expectations (including output - when children are small), flexibility of travelling to meetings etc. and most of all perhaps realizing that mostly science proceeds rather slowly and that trying to do everything in the shortest possible time is neither productive nor profitable long term. In other words, taking a few months off to have children, for example, is not a disaster!

I think we can all agree that mentorship is essential for advancement in any field, not just science. I remember that two of my mentors, David Phillips and Tom Blundell, were both incredibly supportive and made my early career extremely enjoyable and logistically possible. Gender was never an issue, since it was really about the science for them. The importance of having good practical day-to-day arrangements cannot be overstated the practical difficulties of managing small children and having a career are often overwhelming - but are manageable with good planning and an understanding attitude from all concerned. I've always felt - this is another joy of working in science - that I've never worked for somebody, and nobody's ever worked for me; we've always worked together as colleagues whether it's a student or, when I was a student, a professor. We were really equal partners in the game.

\section{What is the biggest career hurdle that you have had to overcome?}

CD: I don't think there was one big hurdle. Probably a key turning point -although I didn't realize it at the time was when I was offered the post-doctoral position in a new biotech lab in California. The lab developed many tools for plant genetic engineering right at the beginning of that technology. I was impressed with the can-do attitude I found there.

MO: Learning German!

AO: In general the biggest challenge has been having children at the time in my career when I've been establishing my independence. My productivity obviously decreased over this time but building it back up wasn't as hard as I expected. Having children also slowed down my progression into senior roles but not as much as I thought it would. The most significant impact for me has not being able, or wanting, to travel. Conferences are places where your work gets recognized, your face gets known and you are seeing cutting edge and unpublished research. There are no metrics that really take that into account. Being in Australia means that any international conferences require quite a time commitment. Because my husband does not have flexible holidays I couldn't take the whole family so for me it has not been feasible to go to international conferences in the last 5 years. However, expect to see me around in the next 5 years! 
JT: I have had many hurdles in my career but they have mostly been around answering difficult scientific questions. I would say that a significant challenge many women scientists face is not around one event, but a general lack of confidence. Even when I was offered my current job I deliberated for a long while before accepting, questioning whether I was capable of doing it. I remember thinking at the time: if I were a man and was offered this job, would I have such a dilemma?

\section{What advice would you give to an undergraduate/ graduate regarding a career in research?}

CD: If you have a passion for science, then keep going no matter what. Don't be put off by apparent difficulties - for example, it would seem impossible to be a post-doc or run a group and start a family at the same time. But it is manageable and in fact the period when the children are young and thus most exhausting is actually relatively short. If you have the vision you will always succeed. I would always recommend going to labs abroad as part of your training - it makes a big difference to your horizon setting.

MO: Go to the best lab you can as a graduate student. As a post-doc get experience abroad again in a lab at the forefront of the field you have chosen. And get a mentor. Realize that a career in scientific research means solving problems and this can be fun but is hard work, stressful and internationally competitive; develop a career plan sooner rather than later. For women, insist that your contributions to science are judged by objective standards, and that your access to resources is equivalent to those of your male colleagues at each career stage.

AO: To have a career in research you need to be selfmotivated; you need to have a drive for discovery or achievement. It is not true, however, that this has to be your only motivation in life. You may not know it, but there are many scientists out there who have great research careers and a great family life or another special area of their life. In this regard I think it's very beneficial to talk to mentors and peers about how they manage their careers. For women considering having families it's worth thinking about how you can build support networks with family and friends. My other piece of advice is to step back and look at the big picture. You will spend a lot of intense time with your children in their first few years but you may have another 40 years of your career ahead of you.

JT: I would say that it is very beneficial to work in different labs, maybe changing technology but remaining focused on what interests you most. Also to work with people who have different scientific approaches, who are good scientists and have complementary talents - it is absolutely vital (as well as enjoyable) to form great collaborations and friendships in your career. If you've chosen a career in bioinformatics, I would also add that it's very important to make your data - and your software available to the community. This can be a good source of citations but it is a good way to be visible and feel useful. In the end, I truly believe that you have to find your niche, one you truly enjoy - and one must always follow excellent science.

When I look back on my career, overall I think I sacrificed less than I gained. As a scientist, I appreciate the things in science that other careers can't offer - in particular, the freedom to mentally explore the world around us. That is really spectacular. There are so many advantages - especially if you're a woman - to working in bioinformatics. If you're thinking about choosing it as a career, I would say go for it! It's just so wonderful to see a whole research field advance so dramatically, to learn things that you didn't even conceive of in the beginning. For me, seeing the whole of biology develop and being a part of it - even a tiny, small part - is pure joy.

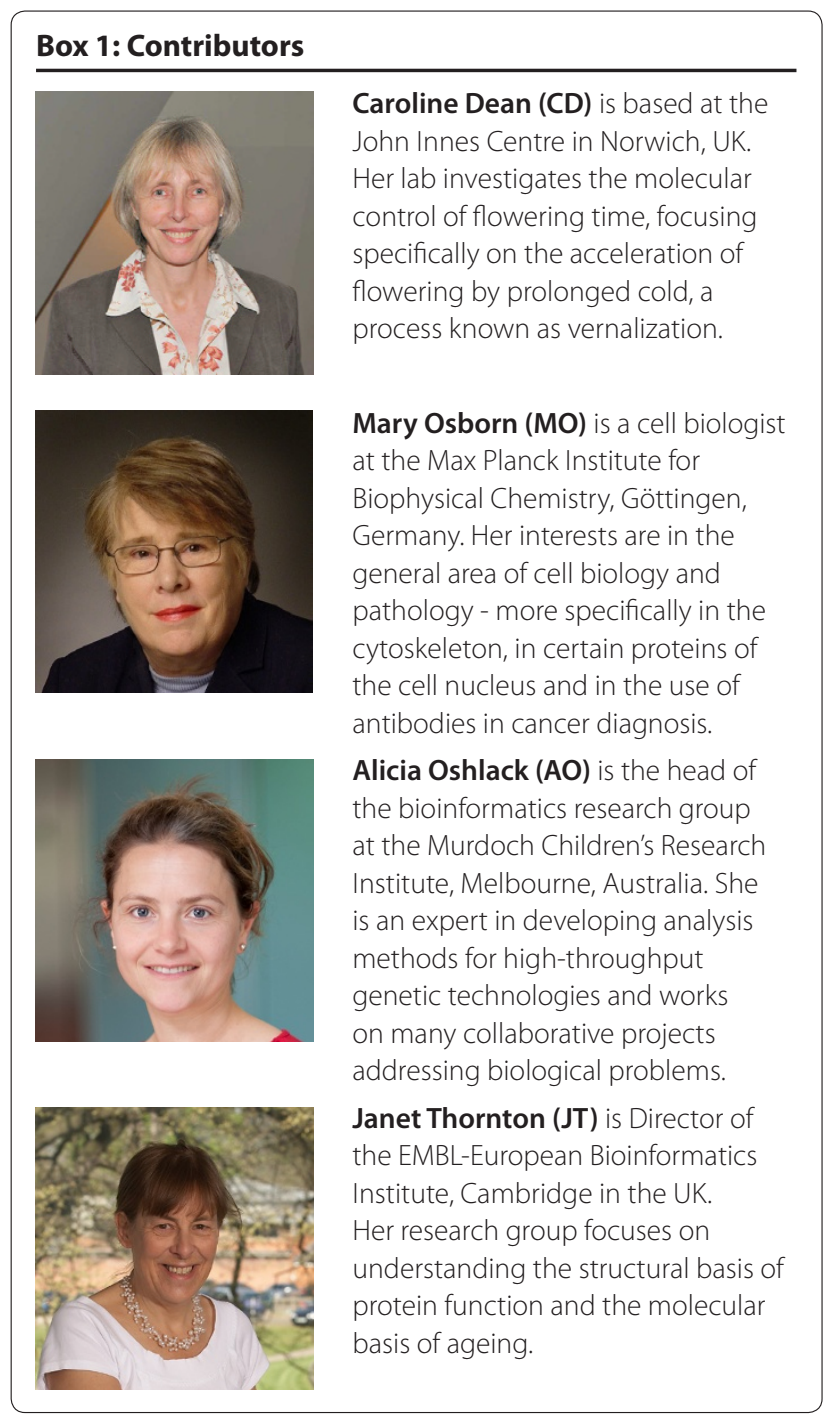




\section{Published: 8 March 2012}

\section{References}

1. Neugebauer KM: Keeping tabs on the women: life scientists in Europe. PLoS Biol 2006, 4:e97.

2. Bell S: Women in Science: Maximising productivity, diversity and innovation. Federation of Australian Scientific and Technological Societies 2009 [http://scienceandtechnologyaustralia.org.au/wp-content/ uploads/2011/06/2009report_wise.pdf]
3. She Figures 2009: Statistics and Indicators on Gender Equality in Science [http://ec.europa.eu/research/science-society/document_library/pdf_06/ she_figures_2009_en.pdf]

doi:10.1186/gb-2012-13-3-148

Cite this article as: Genome Biology: Women in Science. Genome Biology 2012, 13:148. 